\title{
Bowel Preparation
}

National Cancer Institute

\section{Source}

National Cancer Institute. Bowel Preparation. NCI Thesaurus. Code C62659.

Purging and cleansing of fecal and other matter from the bowel to assure subsequent clear evaluation of the bowel or to limit complications due to accidental surgical bowel perforation. 